NOTAS Y DISCUSIONES

\title{
Multiculturalismo. Una revisión crítica
}

\author{
MARÍA HERRERA LIMA \\ Instituto de Investigaciones Filosóficas \\ UNAM, México
}

El término «multiculturalismo» refiere a un conjunto de problemas de índole diversa, muchas veces confuso en sus límites y criterios de diferenciación. No es lo mismo hablar de la situación de los emigrantes en los países desarrollados, por ejemplo, Alemania o los Estados Unidos, que de las minorías étnicas largamente arraigadas en esos mismos territorios o en otros; o de los reclamos «nacionalistas» de pueblos cuya historia los condujo a quedar bajo la tutela de un Estado heredero de conquistas imperiales. Tampoco pueden asimilarse al tema de la «diferencia» en un sentido muy general problemas de naturaleza distinta, tales como la diferencia de género, y otros, aun cuando éstos puedan dar lugar a la formación de grupos sociales con demandas de reconocimiento no satisfechas y reclamar para ellos alguna forma de tratamiento preferencial compensatorio - como las «cuotas" de ingreso a las universidades o lugares de trabajo-y en ese sentido adoptar frente al Estado una postura semejante a la de las minorías étnicas. De modo que las demandas de pluralismo político --para reconocer, por ejemplo, a nuevos sujetos o agentes sociales- no siempre coinciden con problemas de diversidad cultural o de relaciones interétnicas.
Así, una de las primeras tareas al estudiar este tema tendría que ser la de distinguir y delimitar campos y ámbitos de relevancia para cada problema, y con ello, avanzar en la búsqueda de soluciones! Además de señalar que los mismos problemas son de hecho considerados de maneras diferentes por los estudiosos, algunas veces de manera complementaria, otras en cambio desde perspectivas que no permiten visiones de conjunto más $o$ menos coherentes. En esta etapa preliminar de identificación y esclarecimiento resulta importante, sin embargo, intentar considerar hasta donde sea posible contribuciones emprendidas desde diferentes disciplinas, por ejemplo: aspectos de integración económica y formas de desarrollo alternativo, modos de asociación local, formas de representación colectiva, o estudios de campo sobre movimientos sociales, y no sólo consideraciones teóricas de derechos o en torno a las autonomías regionales o de grupos, etc. Aunque por ahora tendremos que contentarnos con señalar caminos y posibles orientaciones y relaciones entre campos de problemas, más que intentar respuestas puntuales.

Desde la optica más restringida de la filosofia y teoría politica - a la que habre- 
mos de limitar nuestra revisión críticatendríamos que destacar un cambio importante de orientación ante estos problcmas en las polémicas recientes. Si hace algunos años los temas a discutir se referían a problemas tales como los de la racionalidad de las creencias, o las contradicciones del relativismo cultural ${ }^{2}$, y más adelante se presentaría como un enfrentamiento entrc posturas individualistas y comunitaristas en teoria moral ${ }^{3}$, ahora las preocupaciones se refieren a cuestiones políticas más inmediatas; a problemas urgentes que demandan solución y que exigen ser vistos desde el punto de vista de quienes sufren sus consccucncias, por ejemplo: las violaciones a los derechos humanos de los emigrantes, o las condiciones de marginación y pobreza de las minorías étnicas, o reclamos de autodeterminación de pueblos que han recuperado un sentimiento nacional al desmembrarse viejas hegemonias, entre otros. Podria hablarse de una nueva sensibilidad en tiempos de crisis, aunque de alguna manera éste ha sido siempre el caso, si pensamos, por ejemplo, en las diferentes formulaciones históricas del concepto de tolerancia. Como nos recuerda Susan Mendus, éstas surgieron precisamente en momentos críticos de persecución religiosa, o discriminación racial o sexual ${ }^{4}$. Por ello, muchas de sus formulaciones conceptuales conservaron las huellas de sus orígenes y plantean más tarde dudas sobre la aplicabilidad o validez de las soluciones propuestas desde horizontes de problemas diferentes, lo que, por otra parte, hace necesaria su reconsideración.

Dentro de la filosofia política, el debate actual sobre el multiculturalismo gira en buena medida en torno a los intentos de ajustar o modificar el modelo político liberal para dar respuesta a los problemas que plantea la nueva situación mundial, ya que el viejo modelo de pluralismo parece insuficiente ante la mayor complejidad de las relaciones entre grupos social y cultural- mente heterogéneos en el ámbito de los Estados nacionales y más allá de ellos. Aunque en la etapa anterior del debate los comunitaristas habian planteado ya $-\mathrm{y}$ continúan haciéndolo- la necesidad de superar este modelo ${ }^{5}$ en el presente trabajo nos limitaremos a considerar la perspectiva interna a la teoría política liberal, prevaleciente como modelo en los Estados democráticos.

La caracterización de la relación frente a las culturas tradicionales que planteaba la primera teoría antropológica como una relación entre mundos relativamente autocontenidos y aislados (o «inconmensurables») resulta poco relevante en el contexto de una cconomía globalizada, de importanles movimientos migratorios y de refugiados, y de demandas crecientes de minorias étnicas, que ciertamente no son nuevas, pero que han adquirido mayor visibilidad internacional gracias a los nuevos medios de comunicación de masas. No es en absoluto despreciable el peso que ha tenido, por ejemplo, el apoyo internacional $y$ de organizaciones no gubernamentales para la supervivencia del movimiento indigena en Chiapas. Fstos grupos marginados, minoritarios o no, han dejado de estar "sumergidos" en el tejido de una cultura dominante que los ignoró por mucho tiempo y para la que resultaban «invisibles», como diría Michael Walzer al mencionar la escasa influencia que tuvo la presencia de los indios americanos, y aun de los negros, en la determinación de los rasgos más sobresalientes de la concepción del pluralismo político norteamericano ${ }^{6}$. O como en el caso de los grupos indígenas mesoamericanos, cuyas necesidades particulares y especificidad cultural han sido sistemáticamente ignoradas en la constitución política de los Estados poscoloniales.

De manera que, a pesar de las diferencias en la naturaleza de los problemas ya mencionados, existen algunos puntos de 
convergencia en la discusión teórico-política: por un lado, los que se refieren al tipo de instituciones que deben atcnderlos $-y$ que pretenden expandir cl modelo del pluralismo político para incluir el multiculturalismo-, y por otro, a ciertas posturas comunes que adoptan los sujetos políticos que presentan demandas al Estado como agentes colectivos y no sólo como individuos. Estos casos tendrian en común la idea de apelar a «derechos colectivos" $y$, con ello, plantear un conflicto a la concepción individualista del derecho del Estado liberal. Ésta scrá cicrtamente una de las preguntas clave del debate: ipuede postularse de manera coherente esta clase de «derechos $»$ ?, ¿pueden apelar los individuos a formas de membrecia social -0 étnica, o de género, o de otra naturalezaen sus demandas al Estado?, Lcómo conciliar esta clase de demandas con el reclamo fundamental de igualdad ante la ley, o frente a una concepción de la justicia como imparcialidad?

Éstos han sido viejos problemas para la teoría política, y la presencia de diferencias culturales radicales (lengua, usos y costumbres) ha supucsto sicmpre un caso «limite» para el liberalismo; éste ha sido históricamente capaz de acomodar algunas diferencias pero no otras. $O$ dicho de otro modo: ha podido hacerse cargo de aquellas diferencias culturales (como las de creencias religiosas) siempre y cuando éstas se mantengan en el ámbito privado y no interficran con las instituciones políticas ni las leyes de un Estado liberal que se proclama «neutral» frente a dichas diferencias. Esto no es de sorprender si recordamos que en sus origenes la teoria liberal fuc, al menos en parte, una respuesta a las guerras de religión en la Europa de la primera modernidad. Para algunos de los teóricos del liberalismo, como John Rawls, este caso histórico constituye precisamente el modelo del pluralismo político liberal, al menos en algunos de sus aspectos centrales que se mantienen vigentes en su programa de justificación filosófica. Cabe mencionar que aun en su más reciente versión del Liberalismo Político, en el que juega un papel más importante la idea de tolerancia, se mantiene una «estrategia de exclusión» (como la llama Kenneth Baynes) que consiste en climinar de la agenda política los temas más conflictivos, o aqucllos acerca de los cuales no puede conseguirse un consenso?

Es menester distinguir, no obstante, entre diferentes concepciones del pluralismo (o de la idea de tolerancia a la diversidad de creencias, valores y prácticas sociales) en la historia del pensamiento político que a grandes rasgos puede ser considerado como liberal. Podríamos proponer al menos dos grandes versiones o «modelos» de pluralismo político que scñalan a su vez momentos decisivos en la historia del pensamiento y las instituciones políticas: la primera etapa, que corresponde a la constitución de los Estados nacionales, propone la idea de una nueva conciencia ciudadana más allá de las identidades tradicionales ligadas a afiliaciones rcligiosas o étnicas, y define las características de la teoría libcral en general, y de alguna manera incorpora también el caso cspecial de los Estados Unidos como una nación de emigrantes. Después, la segunda etapa o modelo del «Estado benefactor» que responde a una situación social distinta: ante la presencia de nuevos agentes políticos surgidos de movimientos sociales - como las luchas contra cl racismo o contra la discriminación tacial o de género, etc. - que expande la intervención del Estado y plantea la defensa de derechos de grupos específicos, y que como tal desborda los límites del viejo liberalismo y se accrea a modelos de tipo corporativo en la adjudicación de derechos y formas de representación política. Las fronteras entre ambos son, sin embargo, borrosas, así como el alcance que se quiera dar al 
segundo modelo de pluralismo político. Para algunos, se trata simplemente de ofrecer un cierto tipo de servicios o tomar medidas para cumplir obligaciones -incluso de carácter moral - para corregir o compensar situaciones de desigualdad social; pero éstas deberán ser vistas como soluciones ad hoc que tendrían como fin conseguir a la larga condiciones de mayor igualdad y, por lo tanto, podrían ser suprimidas con el tiempo. Para otros, en cambio, se trata de un cambio de política sustantivo, que debe incorporar a nuevos agentes sociales como sujetos colectivos, además de reconocer el carácter limitado de la idea de «neutralidad» del Estado, tanto en atención al hecho de que todos los individuos conscrvan alguna clase de afiliación colectiva, como porque estas «marcas de identidad» (lengua, etnia, etc.) juegan un papel importante en las relaciones de poder entre los diferentes grupos que componen los Estados nacionales. Las versiones más moderadas de este nuevo pluralismo - dentro del marco de un Estado constitucional democrático--.- sostienen que no se trata tanto de suprimir la neutralidad del Estado, sino de reconocer que ésta no es munca del todo posible. De manera que lo que se ha llamado un Estado ncutral, es en realidad un sistema de "derechos de grupo», esto es, un sistema que, como dice Will Kymlicka en los Estados Unidos, «apoya la lengua de la mayoría, su historia, cultura y calendario "de conmemoraciones simbólicas" ${ }^{8}$, entre otras cosas. Para los autores de esta orientación no se trata entonces de una modificación sustancial al concepto de derechos políticos liberales, sino de su extensión a los excluidos, aunque esto plantea, por supuesto, el problema de cómo decidir lo que constituye la «identidad nacional» 0 cómo construirla a partir de identidades culturales diversas.

En las versiones contemporáneas del primer modelo se trata ante todo de con- seguir el tránsito de esta segunda forma de pluralismo - que incorpora la nueva heterogeneidad social- a una versión ampliada del primero; como sostiene Michael Walzer, «no es imposible imaginar una sociedad heterogénea pero igualitaria: la heterogeneidad cultural y privada, la igualdad económica y política». En cambio, el segundo modelo de pluralismo político que pretende incluir al multiculturalismo, como indicábamos antes, resulta más complicado. En algunos casos porque sus planteamientos pueden resultar incompatibles con los principios de un Estado democrático liberal (como, por ejemplo, el rechazo o restricción severa de los derechos individuales), y en otros porque las concepciones colectivistas o comunitarias que propone contradicen las creencias más arraigadas de la tradición del pensamiento político liberal. Aquî se plantea al analista del liberalismo un reto importante: el de distinguir entre los supuestos irrenunciables de la teoría y aquellos aspectos de su formulación conceptual que se deben a factores contingentes y podrian ser modificados.

Como señala Susan Mendus, al referirse a los límites del pensamiento liberal en relación a la idea de tolerancia. Esto es, a las «huellas" que conservan estas nociones de los problemas históricos concretos a los que pretendian dar respuesia y que explican sus insuficiencias. Asi, lo que distingue a la idea negativa de tolerancia de Locke (en la Epistola de Tolerantia) como mera defensa contra los intolerantes, como algo que involucra una paradoja: defender el derecho de otros sobre aquello que disgusta o se desaprueba tiene que ver con la necesidad de poner fin a las guerras de religión. Mientras que la idea positiva de tolerancia de J. S. Mill (en On Liberty), que la ve como una virtud, como la capacidad de elección libre de los individuos, como algo que se desprende del concepto mismo de libertad y autonomía personal, 
responde a una etapa distinta de la vida política y el pensamiento europeo ${ }^{9}$. Las dos concepciones tienen, no obstante, un alcance limitado, por ejemplo, la de Locke: se dirige a los intolerantes, pero no dice nada sobre el daño causado a las víctimas; considera la irracionalidad de la intolerancia religiosa, pero no ofrece argumentos en contra de otras formas de intolerancia, etc. La de Mill, en cambio, ofrece un argumento más amplio en favor de la diversidad, e intenta superar la paradoja de la tolerancia apelando a la libertad individual, pero depende de supuestos antropológicos cuestionables. Ambas formulaciones han conservado a pesar de todo una cierta vigencia, y encuentran resonancia todavía en discusiones actuales, por ejemplo: ¿cómo aceptar en las sociedades tradicionales prácticas que consideramos ofensivas o violatorias de la dignidad de las personas? (esto es, icốmo aceptat lo que contradice nuestros principios en nombre de la tolerancia a los diferentes?); la solución de Mill (o de Voltaire) a su derecho a elegir tampoco nos resuelve el problema, ya que, además, cuando se trata de posturas colectivas, siempre cabe la pregunta de si los individuos afectados disponen efectivamente de los medios para decidir acerca de las prácticas o creencias que se les imponen. De este modo, el derecho a la disidencia, y alguna forma de recurso a la justificación de las creencias individuales, resulta un requisito irrenunciable de cualquier postura liberal. En cambio, otras de sus limitaciones podrían atribuirse a motivos políticos 0 de otra indole.

Por ejemplo, resulta contradictoria la consigna «un pueblo, una nación», que, como nos recuerda Michael Walzer, ha acompañado la constitución de los Estados liberales desde sus inicios ${ }^{10}$ y que explica en parte las resistencias a la aceptación de diferencias culturales "radicales" en el seno de las democracias liberales. Esta pro- clamación emblemática oculta con frecuencia la imposición de una lengua y un conjunto de creencias y valores que pertenecen a la comunidad histórica responsable de la unificación del Estado en cuestión, confundiendo así la defensa de una ciudadanía abstracta, ajena a cualquier particularidad étnica o cultural, con aspectos contingentes de una cultura determinada. Dado que en la Edad Moderna el modelo político lo proporcionaron los nuevos Estados nacionales, la idea liberal de tolerancia sólo puede entenderse si ésta se da en condiciones de relativa unidad cultural. Uno de los requisitos para la viabilidad de esos nuevos estados, formados por un conjunto de "pueblos» originalmente distintos, fue el de conseguir la hegemonía cultural como un requisito de estabilidad política - prevenir movimientos separatistas- principalmente a través de la unificación lingüística. Este fue el caso de las naciones europeas modernas y después el de la política de recepción de emigrantes de los Estados Unidos; y, desde luego, podemos agregar nosotros, de los países latinoamericanos herederos de las hegemonías lingüísticas de España y Portugal.

Consecuentemente, se incorporó a la ideología liberal la convicción de una tendencia (más o menos necesaria o inevitable) hacia la «unidad nacional» de todos aquellos que por diversas circunstancias históricas (conquistas militares, movimientos migratorios) diferían en algún rasgo importante (como la lengua) de la cultura dominante. Pero podemos preguntarnos ahora con mayor distancia temporal: ¿hasta que punto el liberalismo debe resultar necesariamente en políticas «integracionistas", aunque de hecho éste haya sido el caso en la práctica en la mayoría de los Estados nacionales?, o, en otras palabras, isuponen todas las formas de epluralismo cultural» una amenaza para las instituciones de las democracias liberales?, y 
si no es éste el caso, icuâles y cómo distinguirlas?

Pareciera entonces que el primer problema conceptual que requiere esclarecimiento es el de la distinción entre las pretensiones de validez generalizable de la tcoría liberal del Estado y los aspectos contingentes de la historia concreta de las democracias liberales en las que esa teoria política se ha desarrollado. Una reconstrucción histórica cuidadosa podría poner de manifiesto la manera en que algunos de los rasgos de dichas teorías surgieron de situaciones específicas, y cómo, en buena medida, sus formulaciones doctrinales fueron respuestas a problemas políticos particulares. Con cllo, esos rasgos podrían ser modificados trente a problemas y situaciones diferontes sin tener que renunciar a los principios fundamentales de la teoría democrática; aunque bien podría tratarse de una concepción de la democracia que desborde el marco liberal.

La relación que hace Walzer del liberalismo norteamericano podría ejemplificar esta clase de proceso ${ }^{11}$ en lo que se refiere a las caracteristicas y límites del sluralismo político. A diferencia de los : istados nacionales europeos, cuyo pluralismo fue la consecuencia involuntaria y muchas veces incómoda de alianzas y conquistas militares, los Estados Unidos constituirian una excepción en la medida en que sus origencs plurales resuitaron del hecho de ser una nación de emigrantes, con la peculiaridad de que dichos emigrantes lo eran por voluntad propia y en calidad de indjviduos. Esta peculiaridad marcó la concepción de ciudadania de los norteamericanos y su concepto más restringido de los requisitos de pertenencia cultural - lo que supondría una ventaja si los comparamos con los europcos-, pero al misno tiempo plantcó una exigencia mayor de unidad lingüistica, transformando esta última en un compromiso «patriótico». De manera que la «americanización» de las oleadas periódicas de emigrantes y el rechazo al bilingüismo (ahora frente al español) se torna parte integral de las convicciones políticas más arraigadas de la teoría liberal norteamericana. Otro caso reciente de expresión de temores ante los efectos disfuncionales del bilingüismo es el de Canadá, a pesar de que podrían esgrimirse contracjemplos a partir de la experiencia de algunos países europeos, como el caso de Suiza.

Otro aspecto en el que la versión norteamericana presenta un individualismo más acendrado es el de su rechazo enfático de formas de representación colectiva, to que lc habría conducido a distorsionar su propia historia, ya que de hecho existen ahora y han existido siempre en la práctica en los Estados Unidos formas de representación política colectiva, como, por cjemplo, las de los grupos de interés. Sin embargo, para aceptar la existencia de estos últimos en tanto que grupos que presentan demandas politicas ha sido necesario «redescribirlos» como reducibles en última instancia a derechos de individuos «libremente asociados». Si bien es cierto que la tcoría política del liberalismo anglosajón, en general, ha privilegiado casi siempre el modelo de las «asociaciones libres» (frecuentomente como representantes do interescses económicos) frente a las distintas versiones de modelos corporativos. Vernon Van Dyke nos recuerda al caso de autores como Hanna Pitkin (en The Concept of Representation), quien considera sólo la representación de individuos, aun cuando las upersonas» de las que habla en algunos casos sean sujetos «artificiales» o kcorporativos" ${ }^{12}$. O el de Carol Pateman (en Participation in Democratic Theory), que no explica cómo - - i el criterio de representación es individual- el Parlamento ingles asigna lugares en la Casa dc los Comunes (The House of Commons) por medio de un sistema de «cuotas" a los ingleses, escoceses, galeses e irlandeses, 
respectivamente. Estas distorsiones ocurren tambien en la caracterización de las nociones de obligación y consentimiento y no sólo en la de representación; Van Dyke menciona como ejemplo de esto último al libro de J. P. Plamenatz Consent, Freedom, and Political Obligation, en el que tampoco se considera la posibilidad de que el consentimiento pudiera surgir de una entidad colectiva, o la obligación ser asumida por un grupo, etc. ${ }^{13}$ No es tanto que estas prácticas sean rechazadas o criticadas, sino que simplemente no se toman en cuenta en la formulación de la reoria.

De modo que la reacción ante las posibilidades de un "pluralismo fuerte», tal y como scría requerido para tolerar la presencia de difcrencias culturales radicales, suele ser negativa en la mayoria de los autores liberales. Existe la convicción arraigada de que cuando un Estado nacional no consigue la unidad cultural (que la política siga a la nacionalidad, o que, como en el caso de los Estados Unidos, consiga la unificación de sus ciudadanos), como diria Walzcr, cl pluralismo fuerte de «un Estado, muchos pueblos» sólo le parece posible en las tiranias ${ }^{14}$, o en cualquier caso, es visto como poco deseable o en exceso riesgoso para los regímenes democráticos. Esta afirmación sustiene no sólo el que deba conscrvarse el Estado nacional como supuesto del marco constitucional, un supuesto tradicional de la teoría liberal, sino que se exige una uniformidad de la cultura dentro de los mismos por razones funcionales o de gobernabilidad, sin que al mismo tiempo se perciba esta condición como una imposición o restricción a las libertades políticas.

Si bicn, por otra parte, tuvieron lugar en los Estados Unidos algunos intentos de resistencia a la «americanización» como integración cultural forzosa, o como obligación de relegar las particularidades de la cultura de origen al ámbito "privado" separándolas de la política, éstos tuvieron un alcance limitado. En términos generales, ni en la práctica ni en los esfuerzos de algunos teóricos del pluralismo cultural norteamericano ${ }^{15}$ se logró proponer un modelo convincente como alternativa al viejo modelo de la libertad de creencias religiosas: esto es, volverlas políticamente inofensivas al renunciar a la posibilidad de presentarlas como demandas colectivas.

Cuando se examina de cerca el modelo del pluralismo liberal se advierte que es mucho menos tolerante de lo que predica ser, en parte por la estrategia reduccionista que marca límites no tanto a lo que pucdc ser tolerado (de hecho, las quejas sobre abusos a la dignidad de las personas, por ejemplo, de índole racial o scxual, más bien lamentan la ausencia de contenidos de valor en las políticas públicas), sino por la manera en que las quejas y demandas pueden ser presentadas y atcndidas, que ignora ofalsifica dos hechos sociales fundamentales: 1) la importancia real de las afiliaciones comunitarias en la conformación de las identidades sociales, y su presencia más o menos encubierta en las instituciones sociales y políticas (como ya mencionamos antes, en los mecanismos de representación política y/o en la atribución de responsabilidades y derechos), y 2) los valores y acontenidos» culturales implícitos en las identidades nacionales (además de la lengua, etc.) quc cuestionan o limitan el concepto de «ncutralidad» de los Estados en sus políticas públicas.

Aun el mismo Walzer, quien acepta las dimensiones contigentes de la doctrina libcral norteamericana - que darian cuenta de su extremo individualismo y la postulada separación tajante entre politica y etnicidad-, no parece en cambio inclinado a aceptar como consecuencia la posibilidad de dispensar estos atributos. Más tien, piensa que se debe a ellos la considerable estabilidad política que han disfrutado los Estados Unidos. Aunque evidontemente existen otras razones para 
explicar el porqué de la aceptación de restricciones a la acción política colectiva en el contexto norteamericano, notablemente: el valor simbólico de pertenecer a una de las nacioncs más poderosas del planeta y el valor real del éxito material (o la promesa del mismo) ofrecidos a los emigrantes como nuevos ciudadanos. Además de que, por otro lado, tenemos motivos también para dudar del éxito tan rotundo de este modelo de pluralismo cultural, puesto que no ha sido capaz de integrar a todos los habitantes de su territorio: comenzando por sus pobladores originales, los indios americanos, para continuar después con los emigrantes no voluntarios, los negros, y los nuevos emigrantes latinoamericanos, quienes considerados en su conjunto no constituyen ya una minoría de escasa importancia, o un factor marginal en el tejido social norteamericano.

Así que de algún modo estaríamos de vuelta al punto de partida al enfrentar el tema del multiculturalismo, ya que el modelo liberal del pluralismo político, al menos en su versión más individualista, parece incapaz de responder a sus problemas. Pero tampoco resultaría satisfactorio simplemente postular la necesidad de incorporar demandas como «derechos" colectivos - de minorias étnicas o de otro tipo- sin considerar los problemas y posibles incoherencias de esta propuesta. Aun sin entrar en consideraciones de carácler legal más puntual ${ }^{16}$, podemos mencionar en primer término el temor, muchas veces justificado por la experiencia histórica, de que las fórmulas colectivistas de organización política resulten, si no totalitarias, al menos intolerantes de la disidencia dentro de sus comunidades.

El conjunto de problemas que nos interesa considerar ahora, como lo he dicho antes, se refieren ante todo a cuestiones políticas, ya que dada la complejidad del tema no podríamos ocuparnos de todos sus aspectos. Desde 1989 Charles Taylor ${ }^{17}$ aconscjaba abandonar los términos de «liberales» $y$ "comunitaristas» para caracterizar la oposición en cuestión, puesto que éstos se refieren sólo a un aspecto del problema, además de que podemos imaginar una gran diversidad de combinaciones posibles entre versiones varias del liberalismo y los comunitarismos (liberales o no). De hecho, no todas las modalidades de la teoría política liberal excluyen necesariamente la posibilidad de representación (y de alguna concepción más o menos restringida o acotada de «derechos") de naturaleza colectiva, sino sólo las versiones más estrechamente individualistas.

Desde una postura como la de Michael Walzer, por ejemplo, no sería imposible proponer un entendimiento diferenciado de «esferas» de competencia y formas de aplicación de la justicia distributiva que tuvieran en cuenta a las comunidades $y$ no sólo a individuos aislados ${ }^{18}$. Walzer parte no tanto de una idea de derechos humanos o naturales, ni de una concepción universalista de las personas, sino más bien de lo que él llama una «concepción pluralista de los bienes» (sociales, públicos). La justicia distributiva se refiere no sólo a los bienes o derechos humanos fundamentales (la vida, la libertad), sino a otros bienes sociales compartidos dentro de comunidades particulares; $y$ las reglas para su distribución no pueden seguir criterios universales, ni aspirar a las certezas «cientúficas» del utilitarismo, sino que son, cuando mucho, «un arte para diferenciar» ${ }^{19}$. $O$, en otras palabras, para establecer de modo prudencial las «reglas» de aplicación de los principios de justicia. De ese modo, parecería acercarse a lo que otros teóricos defensores del pluralismo liberal, como Donald Moon, consideran una posible sintesis de este último con una «estrategia aristotélica», siempre y cuando ésta conceda suficiente espacio a la autonomía de los individuos 20 . 
No obstante, esta «complementaricdad» entre una postura universalista y una regla prudencial que pretendiera, a la manera de Walzer, realizar la justicia de manera diferenciada en situaciones concretas, se consigue al costo de aceptar situaciones parciales de injusticia no sólo como un hecho empírico inevitable - la realidad imperfecta del mundo sobradamente conocida-, sino como parte de la teoría. Esto resulta tal vez más evidente si consideramos lo que dice Walzer sobre las condiciones de umembrecía" a una comunidad nacional determinada, y sobre todo cuando se refiere al problema de los refugiados. $\mathrm{Al}$ plantearse el problema de los refugiados por parte de un Estado-nación se pregunta sobre las razones de la obligación moral de recibirlos y señala dos tipos de afinidades con ellos como posibles «fuentes» de obligaciơn: en primer lugar, estarian aquellos que hubieran sufrido un daño directo del país receptor, o cuya condición precaria o de necesidad extrema fuera el resultado de las acciones de dicho Estado (el caso de los refugiados de guerra, Vietnam como ejemplo en el caso norteamericano). En segundo lugar, todos aquellos que fueran víctimas de represión autoritaria o discriminación injustificada podrían ser vistos como ucompañeros morales de un ciudadano liberal» y se tendría frente a ellos un cierto tipo de deber solidario. Pero esto último, nos dice Walzer, sería llevar la idea de «afinidad» demasiado lejos, y si ésta y no otra (compromiso con un principio universal de justicia) es la fuente de la obligación de ayudarlos no tenemos necesariamente que postularlo como un deber, ya que, nos dice, si nos vemos precisados a elegir entre las víctitimas correctamente tendriamos que volvernos hacia aquellos que tuvieran una conexión más directa con nuestras vidas ${ }^{21}$.

Este ejemplo pone de manifiesto los peligros de aplicación arbitraria de una regla de justicia que no siguiera una orien- tación universalista. No se trata, por supuesto, de sugerit como política pública de ningún Estado en particular la admisión indiscriminada de refugiados, simplemente porque sería una imposibilidad práctica. Se trata, sin embargo, de sostener que las afinidades (o simpatías, o semejanzas, etc.) entre culturas, o pueblos, o comunidades, etc., no son buenas razones para cumplir una obligación moral. El riesgo de arbitrariedad, partidarismo encubierto y auto-engaño acerca de los verdaderos motivos resulta demasiado grande, y en situaciones de guerra, o en conflictos interétnicos, potencialmente desastroso. Si desde la perspectiva de comunidades más o menos aisladas o autocontenidas puede resultar atractiva la solución comunitarista -con ciertas salvaguardias para los derechos humanos y las libertades civiles fundamentales-, en cambio resulta inaceptable cuando se consideran problemas de desplazamientos interculturales o movimientos migratorios fuera del ámbito nacional.

En lo que se refiere al tema de los refugiados, en nuestros días no sólo por motivos de persecución política, sino también por razones económicas, el problema puede ser visto de manera muy distinta si se parte no tanto de las razones hipotéticas de su posible recepción, sino de los argumentos que podrían justificar el uso de la fuerza pública en su contra. Un hecho indiscutible para los refugiados, nos dice Joseph Carens, es el de que «las fronteras tienen guardias y los guardias están armados». Aunque no se discuta el derecho a defender las fronteras de criminales, invasores o terroristas, icómo justificar el uso de la fuerza contra gente pacífica que busca mejores oportunidades para ellos mismos y sus familias? ${ }^{22}$ Carens propone la defensa de "fronteras relativamente abiertas» apoyándose en autores tan diferentes entre sí como John Rawls, Robert Nozick y los utilitaristas, y concluye que desde la 
perspectiva de la concepción liberal de la justicia no hay buenas razones para impedir que los individuos emigren y sean aceptados dentro de los marcos y procedimientos legales de los Estados democráticos. De manera interesante para nuestro tema, responde también a las objeciones planteadas desde la posición de Walzer. Sin reproducir su argumento, podemos señalar que expresa nuestras mismas reservas acerca de acudir a la idea de membrecía como criterio para la asignación de derechos, en este caso, como justificación de exclusiones por haber nacido en un territorio nacional determinado.

Con ello se abre la discusión al tema más amplio de los derechos colectivos. Paradójicamente, al considerar de cerca casos como los de los refugiados, éstos parecen mejor servidos por una orientaciôn universalista de la justicia que por posturas colectivistas aun de tipo restringido como la de Walzer. Ciertamente no se trata de negar la capacidad legítima de los Estados nacionales para imponer condiciones y posibles restricciones de acceso a sus fronteras - al menos dentro de los ordenamientos del Derecho internacional vigentes-, sino de defender dos principios: cn primer lugar, situar la liberad de movimionto de los individuos - y entender de mancra más flexible sus posibles modos de agrupación conforme a patroncs culturales diversos - más allá de los límites de las fronteras nacionales; y cn segundo lugar, evitar cualquicr forma de abuso a los derechos humanos de todas las personas, cualquiera que sea su origen étnico o nacionalidad. Más allá de esto, para autores como Carens, se trata también de reconsiderar la obligación frente a los más desfavorecidos en las consecuencias de las acciones emprendidas por los Estados, inclusive más allá de sus fronteras. Aunque evidentemente una propuesta como ésta requeriría de instituciones de cooperación internacional -0 tal vez de un marco nor- mativo que desborde a los Estados en su conjunto- que aún no existe, si bien ha comenzado a configurarse de manera regional no sólo en aspectos económicos, sino también jurídicos, como, por ejemplo, en la Comunidad Europea.

No obstante, este último no es un modelo fácil de generaljzar, ante todo porque supone una paridad en condiciones de desarrollo que no existe en las relaciones con y entre los países de economías menos desarrolladas, o en sociedades étnicamente más diversificadas. Esto no quiere decir, por otra parte, que no se hayan explorado formulaciones más amplias de pluralismo político para esta segunda clase de situaciones sociales. Como un ejemplo de cstos últimos podemos mencionar los intentos de conciliar la defensa de la libertad individual - $-\mathrm{y}$ el consiguiente derecho a la disidencia - con modalidades de organización política colcctiva y formas de autonomía, ya sea regional o de grupos, según fuera cl caso, en modelos de participación de poder y de autodeterminación por parte de las minorías étnicas ${ }^{23}$. Estos modelos alternativos de pluralismo político pretenden, entre otras ventajas, la de superar los conflictos que se derivan de establecer la membrecia en un grupo o comunidad (aun si se tratara de la «comunidad de ciudadanos liberales" cuando êsta tiene fronteras y requisitos de pertenencia excluyentes) como criterio para la asignación de derechos y deberes. Más bien se intenta explorar formas flexibles de negociación entre grupos que conservan una identidad cultural claramente distinta de la dominante, con los organismos políticos establecidos dentro de los Estados nacionales. En muchos casos, cstos procesos estấn aún cn una fase exploratoria no exenta de dificultades políticas severas, por ello cs difícil predecir resultados.

Existen no obstante investigaciones interesantes sobre la cuestión de los derechos colectivos referidos a aspectos teó- 
ricos sobre su compatibilidad con el marco de un Estado democrático, rebasando las barreras de individualismos estrechos ligados históricamente a circunstancias politicas distintas de las actuales, y de algún modo ya obsoletos. También, en lo que respecta a los aspectos prácticos de la solución de problemas concretos de estas comunidades, tales como solución a demandas de propiedades comunitarias, uso de lenguas diferentes a la «nacional», formas de educación especial y desarrollo económico alternativo, etc. Un nuevo reto a la condición humana presente es el de encontrar nuevas fórmulas para el manejo de la complejidad en las relaciones de lo local a lo global no sólo en el terrreno económico, sino en el cultural, sin perder el punto de vista de un idea de justicia universalista que no es necesariamente incompatible - sino más bien necesaria, como lo hemos visto muy rápida y esquemáticamente en casos como los de los derechos humanos de los refugiados y emigrados económicos- con el respeto a las especificidades culturales y la definición de identidades colectivas en condiciones de libertad para los individuos que forman parte de ellas. Una buena parte de la literatura reciente se ocupa precisamente do estos temas ${ }^{24}$.

Entre los retos a enfrentar está de modo importante el de buscar fórmulas alternativas al modelo corporativista no sólo porque éste contradiga los prejuicios de un liberalismo estrecho -que reduce la nocion de pluralismo político a la tolerancia de elecciones individuales, separadas $o$ ajenas a la vida pública-, sino por sus efectos negativos ya conocidos en la expe- riencia de la acción política colectiva de este siglo. En el contexto norteamericano, Walzer considera en el trabajo aquí comentado las consecuencias contradictorias de los sistemas de acuotas" y los problemas de representación en grupos que no tienen una definición estable, o en comunidades sin una ubicación territorial clara, que no permiten pensar en soluciones del tipo de las autonomías regionales planteadas, por ejemplo, en algunos países europeos, o en el caso canadiense 25

La experiencia latinoamericana, y de manera muy especial la de México, plantea un caso digno de estudio en el tema de las relaciones corporativas en la relación del Estado con las comunidades indígenas. Esta larga historia, que cncontró definición institucional con la creación del Instituto Nacional Indigenista a fines de los años cuarenta, y que estuvo marcada por actitudes aintegracionistas» y paternalistas en sus inicios, se fue transformando on un sistema de control político del Estado por medio de la asignación selectiva de recursos y el establecimiento de formas viciadas de relaciones «clientelares» con sectores particulares de estas comunidades, que han conducido en parte a algunos de los callejones sin salida de los conflictos actuales ${ }^{26}$. Si en algo puede instruirnos este ejemplo es sobre los peligros de esta clase de sistema de relaciones políticas, especialmente cuando tienen lugar en regimenes políticos autoritarios. El significado y definiciones de las relaciones democráticas en el contexto de las sociedades multiculturales o pluriétnicas está, sin embargo, aún en proceso de configurarse. 


\section{NOTAS}

1 Para una bibliografía amplia y actualizata que distingue los diversos aspectos del problema ver W. Kymlicka, The Rights of Minority Culhures (Oxford University Press, 1995), pp. 375-382

2 Como cjernplo de ese debate podemos mencionar a Bryan Wilson, Rationality (Blackwell, 1970), y Mattin Hollis y Steven Lukes, Rationality and Relativism (MIT Press, 1982).

${ }^{3}$ Un texto clave en esa etapa de la discusión fue Michael Sandel, Liberalism and the Limits of Justice (Cambridge University Press, 1982).

4 Susan Mendus, Tolerasion and the Limits of Liberalism (Humanities Press, 1989), p. 1.

5 Ver en este tema Carlos Thiebaut, Los Limites de la Comunidod (Madrid, Centro de Estudios Constitucionales, 1992), y también Michael Kelly (compilador), Universalism is. Communitarism. Contemporary Debates in Frhics, Special Issue, thilosophy and Social Crificism (núm. 3-4, vol. 14, 1988).

"En «PJuralism. A Political Perspective», en Kymlicka, loc. cit., p. 142.

* Ver J. Rawis, Political Liberalism (Columbia University Press, 1993), traducción española: México, Facultad de Derecho/FCE, 1996. También K. Baynes, aLiberal Neutrality: Plualism and Deliberative Politics», Praxis Intemational, vol. 12, núm. 1, 1992, pp. $50-60$

${ }^{3}$ Kymlicka, Introduccción a The Rights of Minority Culures (Oxford University Press, 1995), p. 10.

"Mendus, loc. cit., p. 55.

" «Pluralism. A Political Perspective», en Kymlicka, loc. cat., pp. 139-154.

" Además del trabajo ya citado de Walzer pid. supra) ver Susan Mendus, loc. cit., y John Horton (ed.). Liberalism, Multiculuralism and Toleration (St. Martin's Press, 1993).

12 Van Dyke, \&The Individual, the State, and Ethnic Communities in Political Theory», en Kymlicka, toc. cik, pp. 48-49.

19 Ibidem.

14 Kyulicka, lox. cit, p. 141.

15 Como en los ejemplos citados por Walzer: escritores como Horace Kallen y Randolph Bourne, o popularizadores como Louis Adamic. Cit. en «Pluralism. A Political Perspectivex, loc cat, p. 145.

160 La literatura especializada en este campo es muy amplia, además de lo ya citado ver, W. Kymlicka, Multicultural Citizenship: A Liberal Theony of Minorin Rights (Oxford University Press, 1995), y Judith Baker (ed.), Group Rights (University of Torontu Press, 1994).

* Ver Charles Taylor, aCross-Purposes: The Liberal-Communitarian Debates, en Liberalsm and the Monal Life, Nancy Rosenblum (ed.) (Harvard Universily Press, 1989), pp. 159-182.

18 Michael Walzer, Spheres of Justice $A$ Defense of Pluralism and Equatity (Basic Books, 1983).

19 Ibidem, p. XV (Introducción).

20 J. D. Moon, Constructing Conmunity, Moral Pluralism and Tragic Conflicts (Prinocton University Press, 1993), p. 35.

2: Hidem, p. 49.

22 Joseph H. Carens, «Aliens and Citizens: the Case for Open Borders", en Kyndicka, loc. cit, p. 331.

23 Ver Arend Lijphart, «Self-Determination versus Pre-Determination of Ethnic Minorities in Power Sharing Systemsw, en Kymlicka, toc. cit, pp.278-279.

${ }^{4}$ En el tema de los derechos colectivos ver Nathan Glazer, «ndividual Rights Against Group Rights", en Kymlicka, loc. cit., pp.124-138. También W. Brubaker (comp.), Immizration and the Politics of Citizenship in Europe and North America (University Press of America, 1989), y M. Galenkamp, Individuatism and Collectivism: the Concept of Collective Rights (Rotterdamse Filosotische Studies, Rotterdam, 1993).

25 Tendria que ser objeto de otro trabajo la consideración de la alternativa comunitarista. Ver, por cjemplo, Charles Taylor, Muliculuralism and aThe Politics of Recognition", editado por Amy Gutmann (Princeton University Press, 1992, y edicion revisada y aumentada, 1996).

26 Ver, por ejemplo, Guillermo de la Peña, «La Ciudadanía Étnica y la Construcción de los Indios en el México Contemporáneow, cn Revista Internacional de Filosofia Política, núm. 6, UAM-INNFD, México Madrid, 1996, pp. 116-140 (tambien la Bibliografia alli incluida). 